\title{
Spatial-temporal Evolution of Desertification and Landscape Pattern Change in Hulunbeier Sandy Land
}

\author{
Narisu $^{1}$, Yinshan ${ }^{1,2, *}$, Yushan ${ }^{1,2}$, Yuhai Bao ${ }^{1,2}$, Lina $^{1}$, Baocheng Wei ${ }^{1}$ \\ 1.College of Inner Mongolia normal university geography science, Hohhot 010020, China \\ 2.Inner Mongolian key laboratory of remote sensing and geographic information system, Hohhot
}

010022, China

\section{呼伦贝尔沙地荒漠化时空演化及景观格局变化 \\ 那日苏 ${ }^{1}$, 银山 ${ }^{1,2, *}$, 玉山 ${ }^{1,2}$, 包玉海 ${ }^{1,2}$, 丽娜 ${ }^{1}$, 魏宝成 ${ }^{1}$ \\ 1.内蒙古师范大学地理科学学院, 呼和浩特 010022 , 中国 \\ 2.内蒙古自治区遥感与地理信息系统重点实验室，呼和浩特 010022 , 中国}

\begin{abstract}
Based on the TM and ETM+ Lands at image data of 2000-2014, using the GIS spatial analysis method and visual interpretation methods, we extract the dynamic desertification information of Hulunbeier sand land. The spatial-temporal evolution characteristics of landscape pattern are analyzed on the foundation of desertification information. The results indicated that: (1) The total desertification land area decreased by $2822.59 \mathrm{~km}^{2}$ in Hulunbeier during 2000-2014, and different levels of desertification land area has a reverse trend after 2010, which showed that the environment has improved. (2) During 2000-2014, the center of low desertification land moved $13.58 \mathrm{~km}$ to South, medium and severe desertification land moved $10.99 \mathrm{~km}$ and $27.57 \mathrm{~km}$ to East, respectively, and high desertification land $24.17 \mathrm{~km}$ to northward. (3)In the period of 2010-2014, the intervention effect of humanactivities on the landscape is constantly enhanced, and the composition tends to simple, while the landscape type to uneven orientation development. The Landscape patch shape tended to regulation, and the desertification distribution tends to gather after 2010 .

Keywords: Hulunbeier Sandy Land; Desertification; Spatial-temporal Evolution; Landscape Pattern
\end{abstract}

\section{摘 要}

利用呼伦贝尔沙地 2000-2014 年的 Landsat $\mathrm{TM}$ 和 $\mathrm{ETM}+$ 影像数据, 再将人机交互解译和 GIS 空间分析方法相结合, 提取呼伦贝尔沙地 荒漠化动态变化数据。在上述工作础上, 分析

*通讯作者：银山:yinshan@imnu.edu.cn
呼伦贝尔沙地荒漠化土地时空演化和景观格 局特征。结果表明: (1)2000-2014 年中呼伦贝 尔沙地荒漠化土地从 2010 年起, 各程度的荒 漠化土地面积都有逆转趋势, 减少的总面积是 $2822.59 \mathrm{~km}^{2}$, 因此呼伦贝尔沙地荒漠化有明显 好转趋势。(2)2000-2014 年呼伦贝尔沙地轻度 荒漠化土地重心向南移 $13.58 \mathrm{~km}$, 中度和极重 度荒漠化土地重心均向东迁移 $27.57 \mathrm{~km}$ 和 $10.99 \mathrm{~km}$, 重度荒漠化土地重心向北迁移 $24.17 \mathrm{~km}$ 。(3)2000-2014 年对荒漠化景观的干 预作用不断增强的人类活动致使荒漠化景观 组成趋向简单, 并 2010 年后, 荒漠化景观分 布趋于聚集, 景观斑块形状趋于规则化。

关键词: 呼伦贝尔沙地; 荒漠化; 时空演化; 景 观格局

\section{1.引言}

荒漠化是指由于人类活动, 气候变化在内 的各种影响因素造成的干旱、半干旱和亚湿润 干旱地区的土地退化 ${ }^{[1,2]}$ 。随着人类活动对自 然环境不断增加压力, 加剧了土地荒漠化进程 并且威胁人类自身的生存和发展 ${ }^{[2,3]}$ 。土地荒 漠化作为最严峻的全球性环境问题之一, 引起 了世界各国的高度重视 ${ }^{[4,5]}$ 。中国作为世界上 荒漠化最为严重的国家之一[6], 荒漠化面积较 大的内蒙古呼伦贝尔沙地成为了相关学者们 的研究热点之一[7]。在生态学中对景观格局与 过程之间的关系研究成为了前沿话题。通过对 景观格局的动态研究, 可以准确地把握景观功 能及结构的变化情况 ${ }^{[8,9]}$ 。近年来, 随着景观 生态学的发展, 借助景观指数分析方法, 通过 对景观格局的变化分析来反映沙漠化土地的 变化过程, 对研究沙漠化的发生机制, 发展原 因以及沙漠化生态系统恢复重建都具有重要 的意义 ${ }^{[10,11]}$ 。对认识荒漠化的发生和发展机制 
而言, 荒漠化土地空间格局与过程的关系研究 也是有重要意义的 ${ }^{[12,13]}$ 。

我国北方五大沙地之一的呼伦贝尔沙地, 从地域自然条件来说是属五大沙地中的优越 者。然而, 近百年来, 随着人口的不断增加以 及草地过度垦殖、乱砍滥伐和超载过牧等过度 利用, 破坏了草地脆弱的生态平衡, 导致呼伦 贝尔沙地荒漠化呈现出逐年扩张趋势 ${ }^{[14,15]}$ 。 因此, 分析呼伦贝尔沙地的发展过程, 空间演 化规律及景观格局的变化, 为该研究区的荒漠 化防治提供理论依据是此研究的重要意义。

\section{2. 研究区概况}

研究区位于内蒙古高原最北端的呼伦贝尔 草原,介于 $47^{\circ} 20^{\prime}-50^{\circ} 15^{\prime} \mathrm{N}, 115^{\circ} 30^{\prime}-121^{\circ} 10^{\prime} \mathrm{E}$ 之间。处于呼伦贝尔草原中部的呼伦贝尔沙地 东边为大兴安岭西麓丘陵漫岗, 西至呼伦湖 (达春湖)和克鲁伦河, 南北在蒙古国与海拉尔 河北岸之间。研究区在行政区域上包含了两个 市 (呼伦贝尔市和满洲里市) 以及四个旗（陈 巴尔虎旗、新巴尔虎左旗、新巴尔虎右旗和鄂 温克自治旗) 总面积达 8.36 万 $\mathrm{km}^{2}$ 。呼伦贝尔 沙地为沙质高平原地貌, 地势东高西低, 南高 北低, 微有高低起伏 ${ }^{[16]}$ 。具有北方中温带干 旱、半干旱气候向半湿润气候过渡特征的呼伦 贝尔沙化草地区域有冬春季干旱多风, 严寒而 漫长, 夏秋季温润短暂的气候特点 ${ }^{[15]}$ 。年平均 气温-2- $0^{\circ} \mathrm{C}, 1$ 月平均气温 $-28^{\circ} \mathrm{C}, 7$ 月平均气 温 $20^{\circ} \mathrm{C}$ 。年平均降水量 $235-380 \mathrm{~mm}$, 其中 $70 \%$ 集中于夏秋季节(6-8 月), 蒸发量是降水量的 4-6 倍, 为 1100-1630 mm, 干燥度 112-115, 相对 湿度 $60 \% \sim 70 \%$ 。年平均风速为 $4.5 \mathrm{~m} / \mathrm{s}$, 最大风 速为 $20 \mathrm{~m} / \mathrm{s}$, 全年 8 级以上大风日数平均 30 天 以上。呼伦贝尔沙化草地土壤主要以风沙土为
主, 地带性土壤有栗钙土沙质栗钙土以及隐域 性的沙质草甸土、沼泽土和盐碱土等 ${ }^{[16]}$ 。

\section{3. 数据来源与研究方法}

利用 2000、2005、2010、2014 年植被生 长期 (8 月份) 的 LandsatTM 和 ETM+影像数 据, 通过在遥感影像处理软件 ENVI5.1 中彩色 合成, 辐射校正, 几何校正等影像预处理工作 后将这些影像数据作为底图, 在 Arcgis 10.1 中 进行荒漠化土地人工目视解译。解译工作之后 经过拓扑检查和属性纠错等处理得到呼伦贝 尔沙地 2000-2014 年荒漠化动态变化的数据。 3.1 荒漠化土地分级方法

根据《关于中国三北地区荒漠化分类分级 及参考指正表的修订》, 将呼伦贝尔沙地荒漠 化土地分为风蚀荒漠化、水蚀荒漠化和盐渍荒 漠化三类, 在此基础上又按程度划分为未荒漠 化、轻度、中度、重度和极重度荒漠化等五级 （表 1）。

根据上述荒漠化土地分类、分级系统及参 考前人研究 ${ }^{[17]}$,再根据 TM 影像上不同类型、 不同等级的荒漠化土地显现的特征, 并结合实 地调查得到不同类型荒漠化土地和荒漠化土 地的不同程度解译标志 (表 1)。

\section{2 .荒漠化重心迁移模型}

利用人口地理学中的人口重心原理来研 究是荒漠化土地重心的迁移过程及空间变化 研究的主要内容 ${ }^{[2,18-20]}$ 。本文运用重心迁移模 型计算出呼伦贝尔沙地不同程度荒漠化土地 重心的分布, 并通过荒漠化重心的迁移距离计 算来描述不同程度荒漠化土地的总体变化趋 势和空间变化特征。计算公式为式 (1)。

表 1. 呼伦贝尔荒漠化土地分类、类型特征和解译标志

\begin{tabular}{|c|c|c|c|c|}
\hline \multirow{2}{*}{ 1级分类 } & \multirow{2}{*}{ 2级分类 } & \multicolumn{2}{|c|}{ 类型特征 } & \multirow{2}{*}{ 影像特征 } \\
\hline & & 植被盖度 $(\%)$ & 地生产率下降率 $(\%)$ & \\
\hline \multirow{4}{*}{ 风蚀荒漠化 } & 轻度风蚀荒漠化 & $50-70$ & $<10$ & $\begin{array}{l}\text { 有 } 2 \mathrm{~m} \text { 以下的低缓固定沙丘、农田、草场局部地表有风蚀粗化 } \\
\text { 痕迹或积沙, 植被呈浅红色, 不连续分布。图斑内植被有稀疏 } \\
\text { 的覆沙、风沙土, 呈乳白色或黄色班块 }\end{array}$ \\
\hline & 中度风蚀荒漠化 & $10-50$ & $10-50$ & $\begin{array}{l}\text { 固定半固定沙丘呈条状或斑块状, 红白色斑相间。植被呈红色 } \\
\text { 占 } 30 \% \sim 50 \% \text { 的面积, 白色斑块占 } 50 \% \sim 70 \% \text { 策 }\end{array}$ \\
\hline & 重度风蚀荒漠化 & 10月1日 & $30-10$ & $\begin{array}{l}\text { 半固定半流动沙兵成花斑状, 以浅黄色或黄白色为基底色, 其 } \\
\text { 中夹有少量红色斑点 }\end{array}$ \\
\hline & 极重度风蚀荒漠化 & $<1$ & - & $\begin{array}{l}\text { 流动沙丘呈鳞片状, 波纹清哳, 整体显示为明亮的白色或浅黄 } \\
\text { 色调, 很少有红色斑点 }\end{array}$ \\
\hline \multirow{4}{*}{ 盐溃荒漠化 } & 轻度盐渍荒漠化 & $>50$ & $<10$ & 影像呈浅绿色或浅红色（MSS），盐碱斑块呈斑点状分布 \\
\hline & 中度盐溃荒漠化 & $30-50$ & $10-20$ & 植被分布较少，灰色的盐碱斑块成片分布 \\
\hline & 重度盐渍荒漠化 & 10月1日 & $20-30$ & 灰色盐碱斑块占主体，植被少见 \\
\hline & 极重度盐渍荒漠化 & $<10$ & $>30$ & 影像呈现亮白色, 无植被或非常稀疏 \\
\hline \multirow{4}{*}{ 水蚀荒漠化 } & 轻度水蚀荒漠化 & $<10$ & $>30$ & $\begin{array}{l}\text { 有较强的线形纹影, 植被呈浅红色, 不连续分布, 图斑内稀疏 } \\
\text { 的覆沙、沙黄土呈乳白色或黄色斑块 }\end{array}$ \\
\hline & 中度水蚀荒漠化 & $10-30$ & $20-30$ & $\begin{array}{l}\text { 线形纹理明显, 植被呈浅红色斑块, 面 } \\
\text { 积小于 } 30 \%\end{array}$ \\
\hline & 重度水蚀荒漠化 & $30-50$ & $10-20$ & $\begin{array}{l}\text { 线形纹理十分明显, 植被呈浅粉色 } \\
\text { 小玨状, 块状分布, 面积小于 } 20 \%\end{array}$ \\
\hline & 极重度水蚀荒漠化 & $>50$ & $<10$ & $\begin{array}{l}\text { 线形纹理充满整个图斑。植被呈浅粉色, 斑点状分布, 面积小 } \\
\end{array}$ \\
\hline
\end{tabular}




$$
X_{t}=\sum_{i=1}^{m}\left(C_{\mathrm{ti}} \times X_{i}\right) / \sum_{i=1}^{m} C_{t i} \quad Y_{t}=\sum_{i=1}^{m}\left(C_{\mathrm{ti}} \times Y_{i}\right) / \sum_{i=1}^{m} C_{t i}
$$

$X_{t}, Y_{t}$ 分别表示第 $t$ 年管分布的经纬度坐标, $C_{\mathrm{ti}}$ 表示第 $t$ 年第 $i$ 种景观类型的面积, $X_{i}, Y_{i}$ 分别表示第 $i$ 中景观类型斑块重心 的经纬度坐标。

\section{3 景观格局分析}

近年来土地荒漠化景观格局动态研究中 广泛地应用于景观格局指数 ${ }^{[18]}$ 。根据研究区 荒漠化情况, 在景观水平上选取斑块个数 (NP)、多样性指数 (SHDI)、景观形状指数 (LSI)、斑块密度 $(\mathrm{PD})$ 、均匀度指数 (SHEI)、 聚集度 (AI)、平均斑块面积 (AREA_MN) 等 7 个指数。是在景观分析软件 Fragstats 4.2 下完 成景观指数计算的。

\section{4 .结果与分析}

\section{1. 荒漠化动态变化分析}

\subsection{1. 荒漠化土地面积变化}

根据解译得到的呼伦贝尔沙地 2000-2014 年荒漠化土地类型, 利用 ArcGIS 空间叠加分
析模块对解译得到的 4 期荒漠化数据进行叠 加计算, 分别制出 4 期的荒漠化土地面积变化 图和 3 个时段的荒漠化土地转移矩阵 (图 1 和 表 2)。

从图 1 和表 2 中可以看出, 2000-2005 年 轻度和中度荒漠化明显减少, 分别减少 166.52 $\mathrm{km}^{2}$ 和 $1600.84 \mathrm{~km}^{2}$; 且 $1724.34 \mathrm{~km}^{2}$ 面积的轻 度荒漠化土地逆转为非荒漠化土地, 而面积为 $1034.89 \mathrm{~km}^{2}$ 的中度荒漠化土地发展为重度荒 漠化土地; 重度荒漠化增加 $1069.95 \mathrm{~km}^{2}$, 极 重度荒漠化面积增加 $316.65 \mathrm{~km}^{2}$ 。总体上来 看，2000-2005 年的荒漠化减少总面积为 $380.76 \mathrm{~km}^{2}$; 轻度和中度荒漠化土地均呈现逆 转的趋势, 但极重度和重度荒漠化土地面积仍

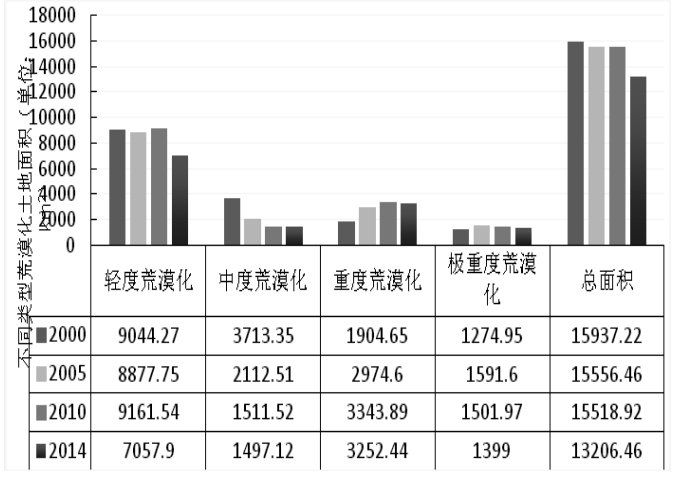

图 1. 呼伦贝尔沙地不同时期荒漠化面积

表 2. 呼伦贝尔沙地不同类型荒漠化土地转移矩阵

\begin{tabular}{|c|c|c|c|c|c|}
\hline 非荒漠化 $/ \mathrm{km}^{2}$ & 轻度荒漠化 $/ \mathrm{km}^{2}$ & 中度荒漠化 $/ \mathrm{km}^{2}$ & 重度荒漠化 $/ \mathrm{km}^{2}$ & 极重度荒漠化 $/ \mathrm{km}^{2}$ & 总计 $/ \mathrm{km}^{2}$ \\
\hline 66030.07 & 793.47 & 301.76 & 215.40 & 351.49 & 67692.19 \\
\hline 1724.34 & 7216.36 & 52.05 & 16.89 & 34.63 & 9044.27 \\
\hline 288.48 & 727.41 & 1592.26 & 1034.89 & 70.31 & 3713.35 \\
\hline 20.15 & 71.40 & 91.90 & 1692.98 & 28.21 & 1904.65 \\
\hline 9.92 & 69.11 & 74.54 & 14.43 & 1106.95 & 1274.95 \\
\hline 68072.95 & 8877.75 & 2112.51 & 2974.60 & 1591.60 & 83629.40 \\
\hline 66815.98 & 944.10 & 51.72 & 68.13 & 193.02 & 68072.92 \\
\hline 1127.93 & 7630.00 & 45.11 & 55.84 & 18.87 & 8877.75 \\
\hline 81.19 & 332.36 & 1303.66 & 373.55 & 24.41 & 2112.54 \\
\hline 38.58 & 186.72 & 33.62 & 2708.82 & 6.85 & 2977.23 \\
\hline 47.16 & 68.35 & 77.42 & 137.54 & 1258.82 & 1591.60 \\
\hline 68110.85 & 9161.54 & 1511.51 & 3343.89 & 1501.97 & 83629.40 \\
\hline 67809.89 & 121.65 & 10.54 & 123.48 & 44.96 & 68110.51 \\
\hline 2404.93 & 6730.14 & 12.08 & 7.46 & 6.94 & 9161.54 \\
\hline 143.78 & 116.46 & 1232.87 & 4.63 & 11.10 & 1511.51 \\
\hline 51.79 & 45.82 & 228.59 & 3012.48 & 5.20 & 3343.89 \\
\hline 12.56 & 43.83 & 13.04 & 104.39 & 1330.80 & 1501.94 \\
\hline 70422.94 & 7057.90 & 1497.12 & 3252.44 & 1399.00 & 83629.40 \\
\hline
\end{tabular}




\section{Risk Analysis and Crisis Response in Big Data Era (RAC-16)}

在扩大, 说明该时段呼伦贝尔沙地荒漠化土地 从总面积上看虽然有逆转的趋势, 但部分地区 的荒漠化现象依然很严重。

2005-2010 年呼伦贝尔沙地荒漠化土地有 所减少, 减少 $37.54 \mathrm{~km}^{2}$; 中度和极重度荒漠 化面积均在减少, 分别减少 $600.99 \mathrm{~km}^{2}$ 和 $89.63 \mathrm{~km}^{2}$, 中度荒漠化逆转轻度荒漠化和转向 重度荒漠化, 其中转化为轻度荒漠化的面积是 $332.36 \mathrm{~km}^{2}$, 转化为重度荒漠化的面积是 $373.55 \mathrm{~km}^{2}$; 极重度荒漠化土地主要向和重度 荒漠化方向逆转, 逆转中度荒漠化的面积为 $77.42 \mathrm{~km}^{2}$, 逆转重度荒漠化的面积为 $137.54 \mathrm{~km}^{2}$; 轻度荒漠化增加 $283.79 \mathrm{~km}^{2}$ 和重 度荒漠化面积增加 $369.29 \mathrm{~km}^{2}$ 。综上分析, 该 时段呼伦贝尔沙地荒漠化土地总面积在减少, 但是重度荒漠化土地面积依然具有增加现象, 说明部分地区的荒漠化现象依然严重, 但比 2000-2005 年的荒漠化现象有一定的改善。

2010-2014 年呼伦贝尔沙地各程度荒漠化 土地面积都有减少趋势, 总面积自 2010 年到 2014 的年减少 $2312.46 \mathrm{~km}^{2}$, 其中轻度、中度、 重度和极重度荒漠化的减少面积分别为 $2103.64 \mathrm{~km}^{2} 、 14.4 \mathrm{~km}^{2} 、 91.45 \mathrm{~km}^{2} 、 102.97 \mathrm{~km}^{2}$; 轻度荒漠化土地减少面积最大, 其次为极重度 荒漠化土地, 而中度荒漠化减少面积最小; 轻 度和中度荒漠化面积减少的原因主要是逆转 为非荒漠化土地, 逆转面积分别是 2404.93
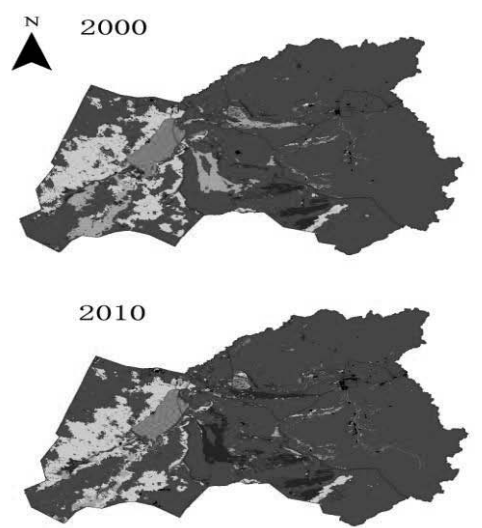
图例

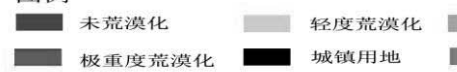

$\mathrm{km}^{2}$ 和 $143.78 \mathrm{~km}^{2}$; 重度荒漠化土地面积减少 的原因则主要逆转为中度荒漠化土地, 逆转面 积是 $228.59 \mathrm{~km}^{2}$, 然而极重度荒漠化土地主要 逆转为重度荒漠化土地, 逆转面积是 $104.39 \mathrm{~km}^{2}$ 。综上所述, 该时段内呼伦贝尔沙 地荒漠化总体上有所好转, 并且各程度的荒漠 化土地均有不同程度的逆转趋势。

\subsection{2. 荒漠化土地空间动态变化}

从图 2 中可以看出, 呼伦贝尔沙地荒漠 化土地主要分布于研究区中部和偏西的新巴 尔虎左旗和右旗、陈巴尔虎旗和鄂温克旗西部 地区。其中轻度和中度荒漠化土地主要分布于 新巴尔虎左旗和巴尔虎右旗; 重度荒漠化土地 主要分布于新巴尔虎左旗和陈巴尔虎旗西部, 极重度荒漠化土地主要分布于新巴尔虎左旗 和右旗。

为进一步观察荒漠化土地在空间上的变 动, 利用重心迁移模型对不同荒漠化类型的重 心坐标进行了计算, 并根据各点的坐标值绘制 了各重心点的空间迁移图 (图 3)。从图中可以 看出, 不同程度荒漠化土地的重心空间分布是 由西向东依次为轻度、中度、极重度和重度荒 漠化土地, 这与该区荒漠化土地的空间分布趋 势完全一致, 说明西部以轻度荒漠化为主, 东 部以重度荒漠化为主, 说明该研究区荒漠化土 地的程度由西向东 (到研究区中部) 呈加重的
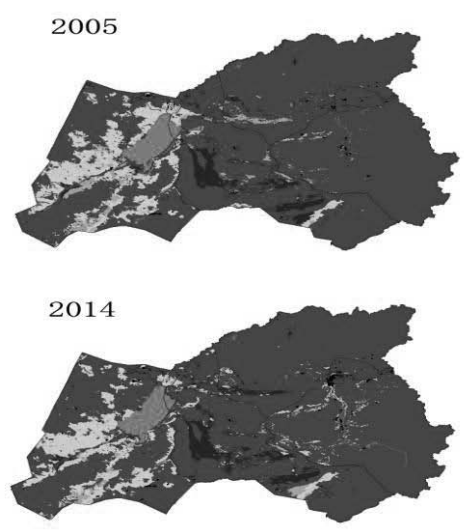

中度荒漠化

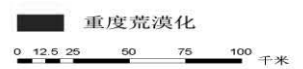

图 2. 2000-2014 年呼伦贝尔沙地荒漠化土地空间变化 
Risk Analysis and Crisis Response in Big Data Era (RAC-16)

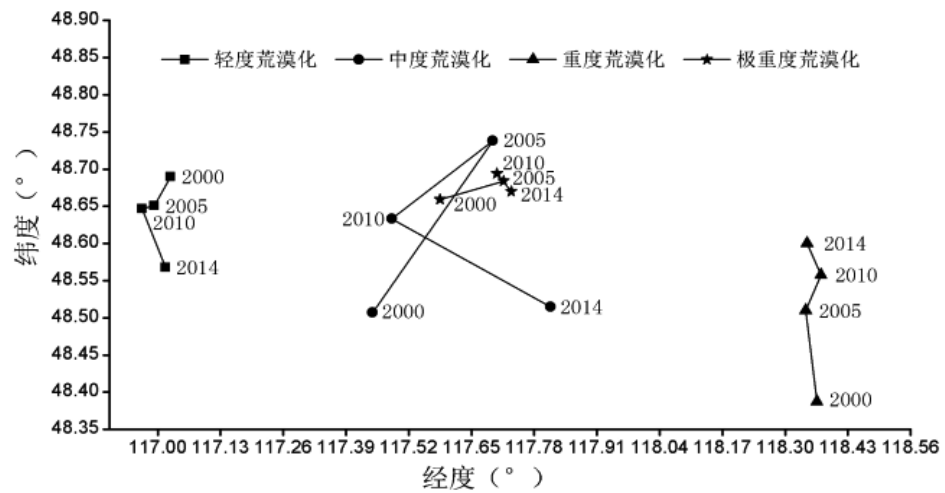

图 3. 2000-2014 年呼伦贝尔沙地荒漠化土地重心迁移

趋势。2000-2005 年轻度荒漠化重心向西北方 向迁移, 迁移的距离不大。中度荒漠化则向东 南方向迁移, 其迁移距离最大, 为 $31.58 \mathrm{~km}$ 。 重度荒漠化重心向正南迁移 $13.83 \mathrm{~km}$ 。而极重 度荒漠化重心向东偏南迁移 $10.04 \mathrm{~km}$ 。

\section{2 .荒漠化景观格局变化分析}

利用景观格局指数计算公式, 以荒漠化整 体为一种景观, 对研究区的荒漠化土地进行景 观格局指数的计算，结果如表 3 。

表 3. 2000-2014 年呼伦贝尔沙地荒漠化土地景观指数变化

\begin{tabular}{cccccccc}
\hline 年份 & NP & PD & LSI & AREA_MN & SHDI & SHEI & AI \\
\hline 2000 & 1031 & 0.0123 & 13.481 & 8109.2144 & 0.6992 & 0.4345 & 91.7799 \\
2005 & 1230 & 0.0147 & 14.4214 & 6797.2358 & 0.6927 & 0.4304 & 91.1197 \\
2010 & 1304 & 0.0156 & 14.5155 & 6411.5031 & 0.6837 & 0.4248 & 91.0493 \\
2014 & 1333 & 0.0159 & 14.3014 & 6272.018 & 0.6157 & 0.3826 & 91.1838 \\
\hline
\end{tabular}

注: NP: 斑块个数（单位: 个）、 PD: 斑块密度（单位: 个 $/ \mathrm{km}^{2}$ )、 AREA-MN: 平均斑块 面积 (单位: $\mathrm{km}^{2}$ )、 LSI: 景观形状指数、SHDI: 多样性指数、SHEI: 均匀度指数、AI: 聚 集度 (单位: \%)

2005-2010 年轻度荒漠化重心稍向西迁移, 迁 移范围小。中度荒漠化重心向西北方向折回 $19.23 \mathrm{~km}$ 。重度荒漠化重心向东南方向迁移, 迁移的距离较短。极重度荒漠化土地重心变化 不大。2010-2014 年轻度荒漠化重心向东北方 向迁移 $9.47 \mathrm{~km}$ 。而中度荒漠化重心迁移距离 为最大，向东北方向迁移了 $27.63 \mathrm{~km}$ 。重度荒 漠化重心向南迁移, 极重度荒漠化重心又折回 向东北方向迁移。2000-2014 年轻度荒漠化土 地重心向南移 $13.58 \mathrm{~km}$, 中度和极重度荒漠化 土地重心向迁移方向相同，均向东迁移 $27.57 \mathrm{~km}$ 和 $10.99 \mathrm{~km}$, 重度荒漠化土地重心向 北移 $24.17 \mathrm{~km}$ ，该时间段极重度荒漠化土地的 迁移最小, 中度荒漠化土地的迁移最大。
2000-2014 年该研究区的斑块个数和斑块 密度均呈现增大, 而平均斑块面积明显减少, 该时段斑块个数增加了 302 个, 其中 $65 \%$ 的斑 块个数是在 2000-2005 年内增长。斑块密度增 加为 0.0036 个 $/ \mathrm{km}^{2}$, 平均斑块面积减少 $1837.1964 \mathrm{~km}^{2}$, 其中 $1311.9786 \mathrm{~km}^{2}$ 的荒漠化土 地在 2000-2005 年之间减少的, 说明破碎化程 度加强, 受人为影响较大。2000-2014 年形状 指数先上升后减少的趋势, 2010 年达到最大 值, 景观形状指数上升表明 2010 之前景观斑 块形状不规则化增强, 容易被周围的其它景观 所影响, 2010 年后荒漠化景观形状指数的下 降, 能够有效说明荒漠化景观斑块形状趋于规 则化, 不易受周围其它景观的影响。在 
Risk Analysis and Crisis Response in Big Data Era (RAC-16)

2000-2014 年荒漠化景观多样性指数和均匀度 指数不断减少, 表明景观的组成趋向于简单 化, 且景观类型向不均匀方向发展,表明起控 制作用的景观类型比支配能力较差的景观类 型起着更主要的作用。聚集度指数先减少后上 升, 2010 年达到最小值, 这说明 2000-2010 年荒漠化漠化土地的分布趋于分散, 2010 后 荒漠化土地的分布趋于聚集。

\section{5. 结论与讨论}

采用 GIS 空间分析方法对呼伦贝尔沙地 2000-2014 年的遥感影像进行目视解译, 再通 过解译结果统计出呼伦贝尔荒漠化土地的时 空分布特征、重心迁移规律及景观格局变化。 研究结果表明:

（1）2000-2014 年呼伦贝尔沙地荒漠化土 地总面积减少 2822.59 $\mathrm{km}^{2}$ 。其中 2000-2005 年 荒漠化总面积虽然在减少, 但重度和极重度荒 漠化土地面积仍在扩大, 到 2010 年重度荒漠 化面积仍然在增加。这表明, 2000-2010 年荒 漠化土地总面积虽然减少, 但是研究区局部地 区的荒漠化仍然较严重; 2010 年后荒漠化土 地总面积不仅减少, 而且各种程度的荒漠化土 地面积也都有逆转趋势, 说明荒漠化现象明显 好转。

（2）呼伦贝尔沙地荒漠化土地的空间分布 图可知, 该研究区的荒漠化土地分布在中部和 偏西的新巴尔虎左旗和右旗、陈巴尔虎旗和鄂 温克旗西部地区; 重心迁移模型可知, 荒漠化 土地重心的空间分布自西向东依次为轻度、中 度、极重度和重度荒漠化土地。2000-2014 年 轻度荒漠化土地重心向南移 $13.58 \mathrm{~km}$, 中度和 极重度荒漠化土地重心迁移方向相同, 均向东 迁移 $27.57 \mathrm{~km}$ 和 $10.99 \mathrm{~km}$, 重度荒漠化土地重 心向北迁移 $24.17 \mathrm{~km}$ 。

（3）2000-2014 年呼伦贝尔沙地荒漠化景 观破碎度变大, 能够反映出人类活动对该地区 荒漠化景观的干预不断的增强; 多样性指数和 均匀度指数不断减少, 表明荒漠化景观的组成 趋向于简单, 并景观类型向不均匀方向发展; 形状指数具有先上升后减少的趋势, 聚集度指 数具有先减少后上升的趋势, 均在 2010 年达 到最大值和最小值, 2010 年后荒漠化景观斑
块形状趋于规则化, 荒漠化土地景观分布趋于 聚集。

2000-2014 年呼伦贝尔沙地荒漠化现象不 断好转是该地区在 2000 年以后实行的保护环 境的 (春季围栏封育, 草场轮牧以及“退耕还林/ 还草”等)一系列的荒漠化治理措施的成果 ${ }^{[15]}$ 。 因此随着政策的不断深入, 该地区荒漠化也不 断的逆转。本研究结果也跟郭坚等人的研究一 致。本文选取的荒漠化土地景观指数能够反映 荒漠景观的斑块的聚合或分离、景观破碎和形 状的变化, 因此能够满足荒漠化土地景观的研 究。从荒漠化景观也可以知道, 对荒漠化景观 的人为干扰不断增加, 荒漠化景观集聚, 荒漠 化景观组成趋向简单化, 也能说明荒漠化现象 好转。景观格局与面积和空间分布结合分析更 有效的说明荒漠化土地的好转与否, 尤其是对 呼伦贝尔沙地荒漠化研究的较少, 因此对呼伦 贝尔沙地的荒漠化土地的面积和空间分布与 荒漠化土地景观结合研究是必要的。

\section{Acknowledgements}

This study was supported by National"Twelfth Five-Year" Plan Project for Science and Technology Support (No.2013BAK05B01) and Natural Science Foundationthe of Inner Mongolia Autonomous Region (No.2013ZD08), and Inner Mongolia Normal University major project to cultivate special project(No.2013Z DPY04) and Inner Mongolia normal university graduate student scientific research innovation fund item (cxjjs 15100)

\section{致谢}

本研究得到了资助项目: “十二五”科技支撑计 划项目资助 (2013BAK05B01) 和内蒙古自治 区自然基（2013ZD08）和内蒙古师范大学重 大项目培育专项项目 (2013ZDPY04) 和内蒙 古师范大学研究生科研创新基金项

(cxjjs15100)。

\section{参考文献}

［1］朱震达.中国土地荒漠化的概念、成因与 防治.第四纪究,1998,18(2):145-155.

[2] 钱大文,巩杰, 高彦净等.近 35 年黑河中游 临泽县荒漠化时空分异及景观格局变化. 干旱区资源与环境 ,2015,29(4):85-90.

[3] 那音太,乌兰图雅,秦福莹 等. 基于 $3 \mathrm{~S}$ 技术 的科尔沁沙地土地荒漠化动态监. 干旱区 资源与环境,2010，24(10): 50-54. 
[4] Schlesinger W H, Reynolds J F, Cunningham G L, et al. Biological feedbacks in global desertification. Science. 1990, 247(4946): 1043-1048.

[5] Dodd J L. Desertification and degradation in sub-Saharan Africa. BioScience, 1994, 44:28-34.

[6] 张道俊.山东玲珑金矿地质特征及深部找 矿潜力分析.地质找矿论从,2006,21(增刊): 39-43.

[7] 徐驰,姜琦刚,李远华 等.呼伦贝尔地区土 地荒漠化动态变化. 世界地 质,2010,29(1):160-167.

[8] 阿如旱, 杨持. 内蒙古多伦县土地沙漠化 景观格局变化特征. 应用生态学报, 2007, 18(11): 2520-2525

[9] 郭红，龚文峰，董隽 等. 基于 RS 和 GIS 的嫩江下游土地沙漠化景观格局变 化特征分析. 生态与农村环境学报, 2009, 25(3):99-103.

[10] 郭丽红,沙占江，马燕飞 等. 环青海湖区 20 年来沙漠化土地景观格局空间变化分 析。中国人口.资源与环境，2010, 20(3):119-123.

[11] 常学礼，于云江，曹艳英 等. 科尔沁沙 地景观结构特征对沙漠化过程的生态影 响. 应用生态学报, 2005, 16(1): 59-64.
[12] 杨光.基于 $3 \mathrm{~S}$ 的盐池县景观格局及荒漠化 动态研 究. 北京: 北京林业大 学, 2008.20-25.

[13] 吴波,慈龙骏.毛乌素沙地景观格局变化研 究.生态学报.2001,21(2):191-196.

[14] 聂浩刚,岳乐平,杨文 等.呼伦贝尔草原沙 漠化现状、发展态势与成因分析.中国沙 漠,2005,25(5):635-639.

[15] 郭坚,薛娴,王涛 等.呼伦贝尔草原沙漠化 土地动态变化过程研究. 中国沙 漠,2009,29(3):397-403.

[16] 玩勤琴.呼伦贝尔沙地沙漠化成因及植被 演替规律的研究. 北京林业大 学, 2008:10-13.

[17] 银山.内蒙古浑善达克沙地荒漠化动态研 究.呼和浩特: 内蒙古农业大学.2010.

[18] 段翰晨,王涛,薛娴 等.科尔沁沙地沙漠化 时空演变及其景观格局. 地理学 报,2012,67(7):917-928.

[19] 包玉海,乌兰图雅,香宝,等.内蒙古耕地重 心移动及其驱动因子分析. 地理科学进 展, 1998, 17(4): 47-54.

[20]贾科利,常庆瑞.陕北农牧交错带土地沙漠 化景观格局动态变化. 应用生态学 报,2007，18(9): 2045-2049.

[21] Y. He. Assessment research of Bijie drought risk based on cloud model. Journal of Risk Analysis and Crisis Response, 2013, 3(4):192-200 